\title{
An 'ethics gap' in writing about bioethics: a quantitative comparison of the medical and the surgical literature
}

\author{
Frederick Paola and Sharon S Barten Nassau County Medical Center, East Meadow, New York
}

\begin{abstract}
In order to determine whether there is a significant difference between the medical literature and the surgical literature in terms of their bioethics content, we conducted a computerized search of the MEDLINE database. The journals searched were selected from the 'Medicine' and 'Surgery' sections of the 'Brandon-Hill List', and the search was limited to 1992 issues of these journals. Three hundred and seven bioethics bibliographic records (out of a total of 11,239 articles indexed) were retrieved from the 15 medical journals searched, while 17 bioethics bibliographic records (out of a total of 2,645 articles indexed) were retrieved from the 12 surgical journals searched. We conclude that there is a statistically significant $(p<0.001)$ difference between the medical literature and the surgical literature with respect to their quantitative bioethics content.
\end{abstract}

\section{Introduction}

We have observed that surgeons are substantially less likely than physicians - or internists as they are known in the US, to attend educational programmes sponsored by our institutional bioethics committee and less likely to avail themselves of the clinical ethics consultation service available at our institution. Thus, out of a total of 32 clinical ethics consultations done at the Nassau County Medical Center between November 1991 and November 1992, 26 (81 per cent) were done on medical patients, while only three (9 per cent) involved patients on surgical services (1). Discussions with members of other area bioethics committees suggest that this is not merely an institutional phenomenon.

Likewise, Simpson (2), drawing upon data collected over a two-year period as an ethics consultant at a Chicago community hospital, reported that 53 out of 59 ( 90 per cent) of requests for ethics consultations came from internists, and only five (9 per cent) from surgeons.

\section{Key words}

Ethics; bioethics; internal medicine; surgery.

\section{Table 1}

\section{Surgical journals searched}

1. American Journal of Surgery

2. Annals of Surgery

3. Annals of Thoracic Surgery

4. Archives of Surgery

5. British Journal of Surgery

6. Journal of Thoracic and Cardiovascular Surgery

7. Journal of Trauma

8. Journal of Vascular Surgery

9. Plastic \& Reconstructive Surgery

10. Surgery

11. Surgery, Gynecology and Obstetrics

12. Surgical Clinics of North America

In order to determine whether the medical literature and the surgical literature reflect this 'ethics gap', we compared the number of bioethics articles published in 1992 in the medical and surgical literature.

\section{Methods}

Since the field of medical librarianship uses the $D$ 'Brandon-Hill List' (3) as one of its core acquisitions and collection development tools, the journals $\tilde{N}$ searched were selected from the 'Medicine' and 'Surgery' sections of this title. Two separate searches were run on a CD ROM version of the MEDLINE $\omega$ database, one for the number of articles dealing with bioethics in the medical journal titles, and one for the number in the surgical journals. The searches were limited to articles in the 1992 issues of all journals.

Twelve journal titles in surgery (Table 1) and 15 journal titles in medicine (Table 2) were searched. Both searches were run against ETHICS and BIOETHICS MeSH (Medical Subject Headings), $\unrhd$ the controlled indexing vocabulary of the National Library of Medicine. These subject headings were 8 'exploded', a function that includes not only the terms searched but all subject headings indexed under them in the indexing hierarchy (for example, $\stackrel{\rightleftharpoons}{\rightleftharpoons}$ 


\section{Table 2}

\section{Medical journals searched}

1. American Journal of the Medical Sciences

2. American Journal of Medicine

3. Annals of Internal Medicine

4. Archives of Internal Medicine

5. British Medical Journal

6. Canadian Medical Association Journal

7. Critical Care Medicine

8. Disease-a-Month

9. Journal of the American Medical Association

10. Journal of Clinical Investigation

11. Lancet

12. Medical Clinics of North America

13. Medicine

14. New England Journal of Medicine

15. Postgraduate Medicine

animal welfare, animal testing alternatives, altruism, conflict of interest, institutional ethics, professional ethics, humanism, morals, and scientific misconduct). The terms BIOETHIC and ETHIC were searched as text words, from the title and abstract of the bibliographic records, and were truncated (for example, BIOETHIC:, ETHIC:) to retrieve any form of the text words beyond those prefixes. The search strategies are depicted in Tables 3 and 4.

Each bibliographic record retrieved was then categorized as either an article proper, an editorial, a letter to the editor, a news item, or a policy statement/position paper (Table 5).

Next, the first author of each article was categorized according to specialty. The specialty was determined by locating the author in the American Medical Directory, (4). Where the directory was not helpful, the original article was consulted for the author's affiliation in order to determine his/her specialty. In those cases where the author's specialty could not be ascertained, the author's specialty was listed as 'unspecified'; no effort was made to contact the involved authors.

\section{Results}

The total number of bibliographic records indexed on the CD ROM version of the MEDLINE database for 1992 from the 15 medical journal titles searched was 11,239 . The total number of bibliographic records indexed on the same database in the 12 surgical journal titles searched was 2,645.

As Table 5 indicates, 307 bioethical bibliographic records were retrieved from the 15 medical journals searched, while 17 bioethical bibliographic records were retrieved from the 12 surgical journals. The difference between the medical and surgical bodies of literature, in terms of the proportion of the literature dealing with bioethics $(307 / 11,239 \mathrm{v} 17 / 2,645)$, was statistically significant $(p<0.001)$. Where the only bioethical bibliographic records considered in the medical literature were those generated by internists, and the only bibliographic records considered in the surgical literature were those generated by surgeons, the difference $(77 / 11,239$ v $14 / 2,645)$ did not reach statistical significance.

\section{SPECIALTY OF THE FIRST AUTHORS - SURGICAL V} MEDICAL LITERATURE

A total of 17 authors with 21 specialties (some authors designated more than one specialty) were obtained in our search of the surgical literature. The distribution of these specialties is depicted in Table 6 .

A total of 307 authors with 345 specialties was obtained in our search of the medical literature. Their distribution is depicted in Table 7.

\section{Discussion}

We found, under the conditions of this search, a statistically significant difference between the medical and the surgical literatures in terms of the fraction of each literature devoted to bioethics (5).

\section{Table 3}

\section{Surgical search strategy}

Search

statement

References retrieved

01 American Journal of Surgery

02 Annals of Surgery

03 Annals of Thoracic Surgery

04 Archives of Surgery

05 British Journal of Surgery

06 Journal of Thoracic \& Cardiovascular Surgery

07 Journal of Trauma

08 Journal of Vascular Surgery

, 185

860

2,369

1,159

1,971

1,569

1,281

1,160

09 Plastic and Reconstructive Surgery

10 Surgery

11 Surgery, Gynecology and Obstetrics

12 Surgical Clinics of North America

1,846

1,280

961

393

131 and 2 and 3 and 4 and 5 and 6

9,113

147 and 8 and 9 and 10 and 11 and 12 and 13

$15 \quad 13$ and 14

16 bioethic: (ti)

16,034

1,246

149

123

17 bioethic: (ab)

19 ethic: (ti)

20 ethic: (ab)

2,496

21 exp bioethics

2216 or 17 or 18 or 19 or 20 or 21

$23 \quad 15$ and 24

24 limit 23 to $\mathrm{yr}=92$ 
Since a substantial number of bibliographic records retrieved from the medical journals were

\section{Table 4}

\section{Medical search strategy}

Search

statement

01 American Journal of the Medical Sciences

02 American Journal of Medicine

03 Annals of Internal Medicine

04 Archives of Internal Medicine

05 British Medical Journal

06 Canadian Medical Association Journal

07 Critical Care Medicine

08 Disease-a-Month

09 Journal of the American Medical Association

10 Journal of Clinical Investigation

11 Lancet

12 Medical Clinics of North America

13 Medicine

14 New England Journal of Medicine

15 Postgraduate Medicine

$16 \quad 1$ and 2 and 3 and 4 and 5 and 6 and 7

178 and 9 and 10 and 11 and 12 and 13 and 14 and 15

$18 \quad 16$ and 17

19 exp bioethics

20 bioethic: (ti)

21 bioethic: (ab)

22 exp ethics

23 ethic: (ti)

24 ethic: (ab)

2519 or 20 or 21 or 22 or 23 or 24

$26 \quad 18$ and 25

27 limit 26 to $\mathrm{yr}=92$
References retrieved

\section{1}

2,331

2,357

1,777

7,558

2,308

1,560

49

5,854

2,477

11,389

415

129

4,779

1,282

18,492

26,374

44,866

1,246

149

123

10,519

3,087

2,496

11,648

1,068

307 'letters to the editor' or 'news items', and since each of these was given the same weight in our study as articles proper - despite the fact that articles would generally tend to be longer - one might legitimately argue that our methods tended to 'inflate' the bioethics content of the medical literature. However, even when the letters and news items were discounted, there remained a statistically significant difference between the two bodies of literature.

We make no assumptions here about which body is of literature contains the more 'appropriate' amount $\overrightarrow{0}$ of bioethics. Perhaps the medical literature contains too much ethics, or perhaps the surgical literature $\vec{\omega}$ too little. Perhaps both statements are true, or $\widehat{O}$ perhaps neither is true. Our concern now is simply this: Why does this disparity exist? Why are fewer articles (as a percentage of the all articles being $\vec{i}$ published) dealing with bioethical issues being o published in the surgical journals than in the medical journals?

Intuitively, it seems that this might happen either because a smaller fraction of bioethics articles received are actually accepted for publication by surgical journal editors, or because fewer such $\notin$ articles are being submitted to begin with. Clearly, these two possibilities are not mutually exclusive.

While we cannot exclude with confidence the first possibility without accessing a representative sample of the manuscripts received and rejected by the

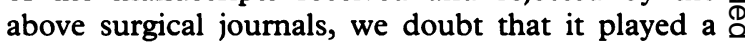
major part in the observed discrepancy. Had it done $\overrightarrow{\overrightarrow{0}}$ so, we might have expected that these rejected $\exists$ articles would find their way into the medical literature. Perhaps some of them did; as can be seen from Table 7, 20 (about 6 per cent) of the bioethics articles in the medical journals were generated by surgeons. However, even if all 20 of these articles had been published in the surgical journals instead of the medical journals, a statistically significant difference $(p<0.001)$ between the two bodies of literature would still remain.

We are left to presume, therefore, that fewer $\frac{D}{D}$ articles dealing with bioethics are being written by

Table 5

\section{Nature of the bioethics articles}

\begin{tabular}{lccrr} 
& \multicolumn{2}{c}{ Surgical journals } & \multicolumn{2}{c}{ Medical journals } \\
& $\#$ & $\%$ & $\#$ & $\%$ \\
Articles & & & & \\
Editorials/commentaries & 8 & 47 & 100 & 33 \\
Letters & 4 & 23 & 32 & 10 \\
News & 3 & 18 & 142 & 46 \\
Policy statements/position papers & 0 & 0 & 26 & 9 \\
\hline Total & 2 & 12 & 307 & 100 \\
\hline
\end{tabular}


surgeons than by contributors to the medical literature (6). Why might this be the case? Again, several possibilities come to mind.

One possibility is that fewer 'bioethical' issues arise in the day-to-day practice of surgery than in the dayto-day practice of internal medicine and other nonsurgical specialties. We reject this idea. Intuitively, it seems only logical that surgeons are confronted daily with the same ethical issues that confront their medical counterparts: 'Is surgery futile in this patient?'; 'Is the promised benefit of surgery in this patient outweighed by its attendant burdens?'; 'Does my patient have the capacity to refuse, or consent to, surgery?'. The list goes on and on. There is simply no a priori reason to believe that the care of the surgical patient is ethically any less complex or interesting than the care of the medical patient.

Rather, we believe that the observed discrepancy is better explained by one or both of the following hypotheses.

First, the relative paucity of bioethical dialogue in the surgical literature may reflect a relatively lesser importance ascribed by surgeons to the bioethics debate. Thus, it may be that due to the procedureoriented, high-tech nature of surgery, there is simply less time in the surgical day and less space in the surgical journals that can be set aside for bioethical discussion.

Still another possible explanation for the discrepancy might be found in the so-called 'surgical personality' (7). Thus, surgeons have been described as being more 'domineering' and 'autocratic' than other physicians (8). Of specific interest to us is a study by Eisenberg (9) comparing the decisionmaking processes of medical and surgical residents, a work cited by Yurt in his Presidential Address to the Surgical Infection Society in 1991:

' $[\mathrm{m}]$ edical and surgical residents early on found

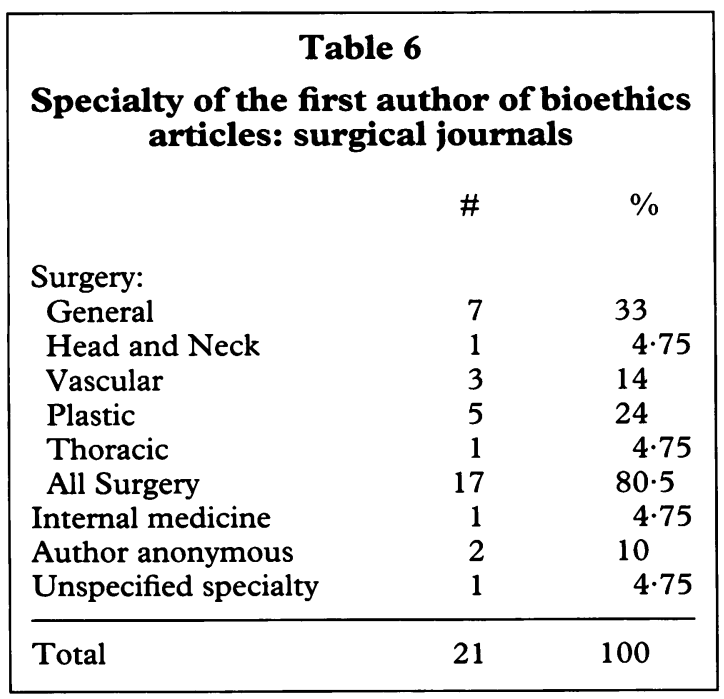

Table 7

Specialty of the first author of bioethics articles: medical journals

\#

$\%$

Internal Medicine

General

Geriatrics

Pulmonary

Nephrology

Cardiology

Gastroenterology

Infectious Disease

Endocrinology

Oncology

House Officer

All Internal Medicine

Surgery

Ob-Gyn

General

Neurosurgery

Cardiothoracic

Orthopaedic

Trauma

Paediatric

All Surgery

Public Health

Anaesthesia

Psychiatry

Critical care med

Gen/family practice

Pathology

Paediatrics

Neurology

Emergency med

Preventive med

Rehab

Radiology

Ophthalmology

'Other'

Correspondent 28

Lawyer

Basic Scientist

Ethicist

Medical historian

Philosopher

Nurse

Veterinarian

Medical student

Economist

Auditor

Total 'other'

Author anonymous

Unspecified specialty

Total

345 
group decision-making equally acceptable. The medical residents did not change between years 1 and 3 , while surgical residents became significantly more oriented toward independent decision-making ... [S] urgical residents also became less tolerant of subordinate decisions; that is, they preferred to make decisions themselves. ... These data document a ... more authoritarian attitude in the developing surgeons than in their medical counterparts (10).

The above characterizations of the 'surgical personality' and surgical decision-making, if accurate, might help explain the relative lack of bioethical dialogue in the surgical literature in a number of ways.

First, it does not seem unreasonable to conjecture that surgeons such as those described above might be more likely than internists to reason and behave paternalistically. Since paternalism 'consists in the judgment that beneficence takes priority over autonomy' (11), one might expect surgeons to identify fewer 'ethical dilemmas' when these two ethical principles come into conflict clinically; and it follows that unidentified ethical dilemmas are not likely to find their way into the literature.

Second, it occurs to us that to the extent that the above characterization of surgeons is true, those surgeons might feel disenfranchised by the presentday bioethics debate, a debate which has branded medical paternalism as 'ethically suspect' (12), a debate in which the ethical pendulum has swung (perhaps too far?) in the direction of the principle of respect for autonomy at the expense of the beneficence principle. In such an atmosphere, surgeons such as those above might perceive themselves to be members of an insular minority, and might be uncomfortable expressing views on bioethics that are at odds with the dominant medical ethos of patient autonomy. Under such conditions, the following statement by Beauchamp and Childress tends to become, in effect, a self-fulfilling prophecy: '[s]o influential is th[e] autonomy model at the present time that it has become difficult to find clear commitments to the traditional beneficence model in contemporary biomedical ethics' (13).

We look forward to future studies designed to elucidate the cause(s) of the observed 'ethics gap', and look forward also to commentary by our surgical colleagues. We believe they have much to contribute to the rapidly changing field of bioethics, particularly in helping to define the concept of medical futility.

\section{Acknowledgement}

We thank the journal's two anonymous referees for their invaluable assistance in the preparation of this manuscript.

Frederick Paola, $M D, \mathcal{F D}$, is Attending Physician in the $\overrightarrow{\vec{*}}$ Division of Internal Medicine, Nassau County Medical $\stackrel{\oplus}{+}$ Center, East Meadow, New York. Sharon S Barten, 든 $M L S$, is Medical Librarian at the Nassau County Medical Center.

\section{References and notes}

(1) Paola F A, et al. Clinical ethics consultation as a part $\overrightarrow{\vec{\omega}}$ of the internal medicine curriculum. Proceedings of $\underset{\mathcal{W}}{\mathcal{W}}$ the Spring Meeting of the American Program Directors of Internal Medicine 1993 Mar 30-31: Washington, DC.

(2) Simpson K H. The development of a clinical ethics consultation service in a community hospital. Fournal oo of clinical ethics $1992 ; 3,2: 124-130$.

(3) Brandon A N, Hill D R. Selected list of books and 옥 journals for the small medical library. Bulletin of the Medical Library Association 1991; 79, 2: 195-222.

(4) American medical directory: physicians in the United States [32nd ed]. Chicago: American Medical $\vec{\omega}$ Association, 1990.

(5) While we considered not limiting our search to the journals selected for small medical libraries, so as to rule out the possibility that a large volume of bioethics articles in 'secondary' surgical journals (not on the core Brandon-Hill list) might bridge the 'ethics gap', we thought it would be too unwieldy a study to cover all the Brandon-Hill titles.

(6) Another possibility which we considered was that $\overline{\bar{\sigma}}$ surgeons might be writing articles on bioethics and $\exists$ submitting them to ethics journals. Towards that end, we began our research on the BIOETHICS? database. Based on several 'key word' and 'subject concept' searches, we concluded that surgeons are $\bar{\Phi}$ contributing less than ten per cent of the total $\bar{\sigma}$ bioethics articles on that database involving the field 3 . of surgery.

(7) Schenk W G Jr. Is there a surgical personality? Current surgery $1988 ; 45,1: 1$.

(8) Zimny G H, Thale T R. Specialty choice and attitudes toward medical specialties. Social science and medicine 1970; 4: 257-264.

(9) Eisenberg J M, Kitz D S, Webber R A. Development N of attitudes about sharing decision-making: $a$ comparison of medical and surgical residents. Fournal $\mathrm{N}$ of health and social behaviour 1983; 24: 85-90.

(10) Yurt R W. The making of a surgeon revisited. Archives of surgery 1992; 127: 16-20.

(11) Jonsen A R, Siegler M, Winslade W J. Clinical ethics [3rd ed]. New York: McGraw-Hill, 1992.

(12) See reference (11): 39.

(13) Beauchamp T L, Childress J F. Principles of biomedical ethics [3rd ed]. New York: Oxford University Press, 1989. 